\title{
COVID-19: transmisión vertical, enfermedad y cuidados en recién nacidos
}

\author{
DOI 10.5377/alerta.v4i1.9916 \\ José Eduardo Oliva Marín ${ }^{1}$, Jorge Alberto Pleitez Navarrete ${ }^{2}$ \\ 1. Colaborador técnico médico, Departamento de Gobernanza y Gestión del Conocimiento. Instituto Nacional de Salud. San \\ Salvador, El Salvador. \\ 2. Neonatólogo. Hospital Nacional de la Mujer. San Salvador, El Salvador. \\ ${ }^{*}$ Correspondencia \\ $\checkmark$ joseduardoliva67@gmail.com \\ (D) 0000-0002-6005-0558
}

\begin{abstract}
Resumen
Existe la posibilidad que el SARS-CoV-2 se transmita tanto verticalmente en el útero, como durante y después del parto. La mayoría de bebés infectados presentan sintomatología leve o son asintomáticos. Las manifestaciones clínicas más frecuentes son la taquipnea y la disnea. En los exámenes de laboratorio, los hallazgos más frecuentes son la leucopenia y la linfopenia. Las lesiones pulmonares se muestran más claramente mediante la tomografía axial computarizada que mediante los rayos X. Las imágenes más comunes en ambas pruebas son las opacidades en vidrio esmerilado. No hay tratamiento antiviral y/o inmunomodulador aprobado para COVID-19 en recién nacidos. Aún no hay disponibilidad de guías específicas para el manejo respiratorio de neumonía por COVID-19 en recién nacidos. Los partos de madres positivas a COVID-19 deben efectuarse en una sala dedicada exclusivamente para ello. La vía de evacuación de elección es el parto vaginal. La evidencia actual no es suficiente para concluir que existe transmisión vertical de SARS-CoV-2 a través de la lactancia materna. Se deben tener precauciones para evitar el contagio posnatal a los recién nacidos y al personal de salud.

\section{Palabras clave}

Recién nacido, infecciones por coronavirus, transmisión vertical, reacción en cadena de la polimerasa, serología.
\end{abstract}

\begin{abstract}
There is a possibility that SARS-CoV-2 is vertically transmitted in the uterus, as well as during and after delivery. Most infected babies present mild symptoms or are asymptomatic. The most frequent clinical manifestations are tachypnea and dyspnea. In laboratory tests, the most common findings are leukopenia and lymphopenia. Pulmonary lesions are more clearly shown by computed tomography than by X-ray. The most common images in both tests are ground glass opacities. There is no approved antiviral and / or immunomodulatory treatment for COVID-19 in newborns. Specific guidelines for the respiratory management of COVID-19 pneumonia, in newborns, are not yet available. Deliveries of COVID-19 positive mothers must be carried out in rooms dedicated exclusively to these patients. The evacuation route of choice is vaginal delivery. Current evidence is not sufficient to confirm SARS-CoV-2 vertical transmission through breastfeeding. Precautions must be taken to avoid postnatal transmission to newborns and health personnel.

Keywords

Newborn, coronavirus infections, vertical transmission, polymerase chain reaction, serology.
\end{abstract}

\section{f ACCESO ABIERTO}

COVID-19: vertical transmission, disease and care in newborns

\section{Citación recomendada:}

Oliva Marín JE, Pleitez Navarrete JA. COVID-19: transmisión vertical, enfermedad y cuidados en recién nacidos. Alerta. 2021;4(1):19-30. DOI 10.5377/ alerta.v4i1.9916

\section{Recibido:}

30 de junio de 2020

\section{Aceptado:}

18 de noviembre de 2020

\section{Publicado:}

22 de enero 2021

\section{Contribución de autoría:} OMJE', PNJA': Concepción de la investigación, búsqueda bibliográfica, redacción, estructuración del manuscrito.

\section{Conflicto de intereses:}

Los autores declaran no tener conflictos de intereses

\section{Introducción}

Actualmente, existen datos que sugieren que el SARS-CoV-2 puede transmitirse verticalmente a través de la placenta en el útero, así como durante el paso del neonato a través del canal del parto. Posterior al parto, la evidencia encontrada sugiere su transmisión horizontal a través de gotas, contacto directo o aerosoles. Esta revisión reune los conocimientos actuales con respecto a la transmisión del SARS-CoV-2 al feto y/o al recién nacido, así como la sintomatología clínica, hallazgos de laboratorio e imagenología más frecuentes. Se completa la revisión con los cuidados que deben recibir los recién nacidos de madres COVID-19 positivas. Aunque el conocimiento actual apoya la transmisión intrauterina del SARS-CoV-2, los casos neonatales diagnosticados a la fecha parecen más bien adquiridos postnatalmente. Por lo tanto, la prevención de su transmisión posnatal es el enfoque que todo recurso de salud debe tener en mente, en cualquier ámbito, en todo momento. 


\section{Discusión de la temática}

\section{Transmisión en útero}

Aunque los estudios a la fecha dejan resultados mixtos sobre si el SARS-CoV-2 puede o no adquirirse en el útero', la ruta transplacentaria se reportó como posible mecanismo de transmisión por primera vez en los Estados Unidos (EE. UU.), el 8 de mayo de 2020. Penfield et al. ${ }^{2}$, utilizando pruebas de reacción en cadena de polimerasa-transcriptasa reversa (RT-PCR, por sus siglas en inglés), reportó la presencia de SARS-CoV-2 en hisopados de placenta en tres embarazadas con COVID-19.

El segundo caso de posible transmisión placentaria fue reportado por Sisman et al. ${ }^{3}$ también en los EE. UU., el 10 de julio de 2020. Mediante inmunohistoquímica, utilizando anticuerpos monoclonales de ratón anti-proteína N del SARS-CoV-2, encontraron una fuerte tinción citoplasmática en las células sincitiotrofoblásticas, compatible con la presencia del virus.

El tercer caso de posible transmisión transplacentaria fue reportado en Francia, por Vivanti et al. ${ }^{4}$, el 14 de julio de 2020. La RTPCR fue positiva en diferentes muestras maternas (hisopado nasofaríngeo, hisopado vaginal, placenta, líquido amniótico y sangre). Se observó una intensa positividad citoplasmática en las células trofoblásticas perivellosas detectadas mediante inmunotinción con anticuerpos antiproteína N del SARS-CoV-2.

Facchetti et al. ${ }^{5}$ reportaron el 17 de agosto de 2020 en Italia, un caso con una expresión robusta de las proteínas S y N del SARSCoV-2 en el sincitiotrofoblasto, detectada mediante hibridación del ARN in situ. Adicionalmente, el análisis ultra estructural identificó partículas virales morfológicamente compatibles con el coronavirus, localizadas en el citoplasma de las células del sincitiotrofoblasto, en el endotelio de los capilares fetales y en las células mononucleares intravasculares fetales. Por primera vez, partículas morfológicamente compatibles con el SARS-CoV-2, fueron localizadas en células mononucleares circulantes fetales. Este entorno histopatológico único de la placenta coincidió con la aparición temprana de COVID-19 en el recién nacido, lo cual es compatible con la transmisión vertical del virus.

Fenizia et al. ${ }^{6}$ reportaron dos casos más en Italia el 12 de octubre de 2020. En el posparto inmediato de dos madres COVID-19 RT-PCR positivas, detectaron la presencia del genoma del SARS-CoV-2 en la sangre de ambos cordones umbilicales, ambas placentas y en la mucosa vaginal de ambas pacientes, así como en la muestra de leche materna de una de ellas. Además, reporta- ron la presencia de anticuerpos lgM e lgG específicos para SARS-CoV-2 en la sangre del cordón umbilical de ambos neonatos, así como en la muestra de leche materna de una de las madres.

Estos resultados sugieren que, aunque rara, la transmisión vertical del SARS-CoV-2 es posible, y que el conocido estado inflamatorio que este virus provoca, puede extenderse a los fetos ${ }^{6}$.

En la Tabla 1 se muestras los resultados de las pruebas diagnósticas efectuadas a los neonatos de los casos previamente descritos.

\section{Transmisión no congénita}

Las rutas no congénitas de transmisión perinatal pueden incluir la transmisión mediante gotas, aerosoles o contacto directo, en la sala de partos o quirófano. Aunque aún no ha sido documentada, tomando en cuenta que el virus ha sido aislado en heces, la vía fecal-oral debe mantenerse en mente como otra posibilidad ${ }^{7}$. De igual manera, ya que el SARS-CoV-2 se ha detectado en el fluido vaginal de mujeres con infección por COVID-19, el contacto directo del neonato con el canal del parto tampoco se puede descartar como mecanismo de transmisión ${ }^{3,4}$. El virus también puede transmitirse mediante gotas, aerosoles o contacto directo, durante los cuidados posnatales en el hospital o en casa ${ }^{8}$.

Otra importante ruta de transmisión postnatal podría ser la lactancia materna. Investigaciones recientes no han encontrado evidencia del SARS-CoV-2 mediante RTPCR o serología en la leche materna, pero el tamaño de las muestras ha sido pequeño! Groß et al. ${ }^{9}$, publicaron en mayo de 2020, la evaluación de la leche de dos madres infectadas con el SARS-CoV-2 durante su embarazo. El ARN del SARS-CoV-2 se detectó mediante RT-PCR en la leche de una paciente en los días 10, 12 y 13 posparto. Aun no queda claro si SARS-CoV-2 puede transmitirse a través de la lactancia materna'.

\section{Epidemiología}

Para octubre de 2020, se encontraron reportes de 526 neonatos de madres con pruebas RT-PCR positivas para SARS-CoV-2 en 40 publicaciones. De estos, tres tuvieron resultados equívocos (IgM o lgG positivas con RT-PCR negativas), dos tuvieron resultados indeterminados (RT-PCR débil, denotando escasa carga viral) y 18 resultados positivos, mediante RT-PCR (Tabla 1). Un total de 423 resultaron negativos y 80 no fueron evaluados con serología o RT-PCR, dado que fueron asintomáticos o presentaron sintomatología leve $e^{2-6,10-22}$ 
Tabla 1. Probable transmisión vertical, características clínicas, de laboratorio e imagenología, de recién nacidos con RT-PCR y/o serología positiva para SARS-CoV-2, de madres COVID-19 positivas confirmadas por RT-PCR

\begin{tabular}{|c|c|c|c|c|c|}
\hline Publicación & $\begin{array}{l}\text { Número de } \\
\text { neonatos }\end{array}$ & $\begin{array}{l}\text { Transmisión } \\
\text { vertical }\end{array}$ & Hallazgos clínicos & $\begin{array}{l}\text { Pruebas SARS-CoV- } 2 \text { y edad a } \\
\text { las que fueron realizadas }\end{array}$ & Imagenología \\
\hline $\begin{array}{l}\text { Wang et al. } .^{24} \\
12 / 3 / 20\end{array}$ & 1 & Posible & Asintomático & $\begin{array}{l}\text { RT-PCR en hisopado } \\
\text { nasofaríngeo, positivo a las } 36 \\
\text { horas de vida. }\end{array}$ & $\begin{array}{l}\text { TAC de tórax } \\
\text { Sombra nodular de alta } \\
\text { densidad debajo de la pleura } \\
\text { del segmento posterior del } \\
\text { lóbulo superior del pulmón } \\
\text { derecho; sombras irregulares } \\
\text { dispersas en los lóbulos } \\
\text { superior e inferior derechos. }\end{array}$ \\
\hline
\end{tabular}

\begin{tabular}{|c|c|c|c|c|c|}
\hline $\begin{array}{l}\text { Yu et al. }{ }^{25} \\
24 / 3 / 20\end{array}$ & 1 & Posible & Asintomático & $\begin{array}{l}\text { RT-PCR en hisopado } \\
\text { nasofaríngeo, positivo a las } 36 \\
\text { horas de vida. }\end{array}$ & $\begin{array}{l}\text { No se le realizaron pruebas } \\
\text { de imagen. }\end{array}$ \\
\hline
\end{tabular}

\begin{tabular}{lll}
\hline Zeng L. et al. ${ }^{26} \quad 3$ & Posible & $\begin{array}{l}\text { El hallazgo más común en } \\
\text { los tres recién nacidos fue }\end{array}$ \\
& & dificultad para respirar.
\end{tabular}

\begin{tabular}{llll}
\hline Zeng H. et al. ${ }^{14} 2$ & de vida. & \\
& & Posible Asintomáticos & $\begin{array}{l}\text { IgM e lgG elevadas en los dos } \\
\text { neonatos, a las } 0 \text { horas de vida. }\end{array}$ \\
& & de imagen.
\end{tabular}

\begin{tabular}{lll}
\hline Alonso et al. ${ }^{27} \quad 1 \quad$ Posible & Al noveno día de vida, \\
& presentó taquipnea \\
& intermitente con \\
& retracciones intercostales \\
& leves, así como dos \\
& episodios autolimita- \\
& dos de desaturación de \\
& oxígeno, durante el sueño \\
& y la alimentación. Los \\
& síntomas resolvieron en \\
& 24 horas. \\
\hline
\end{tabular}

\begin{tabular}{|c|c|c|c|}
\hline $\begin{array}{l}\text { Zamaniyan } \\
\text { et al. }{ }^{18} \\
17 / 4 / 20\end{array}$ & 1 & Posible & Fiebre \\
\hline
\end{tabular}

Chacón-Aguilar $1 \quad$ Posible
et al..21

Neonato de 26 días de vida con historia de fiebre de 12 horas de evolución,

$17 / 4 / 20$

rinorrea y vómitos.

\section{RT-PCR en hisopados}

nasofaríngeos y anales de los tres

neonatos, positivos a las 48 horas

\section{TAC de tórax}

Neumonía bilateral. de vida.

\section{RT-PCR en hisopado \\ nasofaríngeo, positiva a los siete \\ días de vida.}

\section{Rayos X de tórax}

Opacidades en vidrio esmerilado en la región parahiliar derecha.
RT-PCR en hisopado nasofarín- ND. geo, positiva a las 24 horas de vida.

$\begin{array}{ll}\text { RT-PCR en hisopado } & \text { USG transfontanelar y EEG } \\ \text { nasofaríngeo, positiva a los 26 } & \text { normales. }\end{array}$

Además, dos episodios

paroxísticos: el primero, con retroversión ocular e hipertonía generalizada de varios minutos de duración, mientras se alimentaba; el segundo, consistente en hipertonía generalizada con cianosis facial, mientras dormía.

Al examen físico:

Consciente, llanto enérgico e irritabilidad, hipertonía de miembros con reflejos osteotendinosos aumentados, sin clonus. Durante su ingreso presentó además, diarrea. normales. 


\begin{tabular}{|c|c|c|c|c|c|}
\hline Publicación & $\begin{array}{l}\text { Número de } \\
\text { neonatos }\end{array}$ & $\begin{array}{l}\text { Transmisión } \\
\text { vertical }\end{array}$ & Hallazgos clínicos & $\begin{array}{l}\text { Pruebas SARS-CoV- } 2 \text { y edad a } \\
\text { las que fueron realizadas }\end{array}$ & Imagenología \\
\hline $\begin{array}{l}\text { Ng et al. }{ }^{11} \\
6 / 5 / 20\end{array}$ & 1 & Posible & $\begin{array}{l}\text { Disminución del apetito, } \\
\text { letargo, hipotermia e } \\
\text { ictericia, posteriormente } \\
\text { apneas. }\end{array}$ & $\begin{array}{l}\text { RT-PCR en hisopado } \\
\text { nasofaríngeo, positiva a los cinco } \\
\text { días de vida. }\end{array}$ & $\begin{array}{l}\text { Rayos X de tórax } \\
\text { Opacidades moderadas } \\
\text { bilaterales. }\end{array}$ \\
\hline $\begin{array}{l}\text { Coronado } \\
\text { et al. }{ }^{12} \\
7 / 5 / 20\end{array}$ & 1 & Posible & $\begin{array}{l}\text { A las tres semanas de } \\
\text { edad presentó dos } \\
\text { días de congestión } \\
\text { nasal y taquipnea, con } \\
\text { desaturación de oxígeno } \\
\text { al alimentarse. }\end{array}$ & $\begin{array}{l}\text { RT-PCR en hisopado } \\
\text { nasofaríngeo, positiva a las tres } \\
\text { semanas de vida. }\end{array}$ & $\begin{array}{l}\text { Rayos X de tórax } \\
\text { Opacidades lineares } \\
\text { bilaterales y consolidación } \\
\text { del lóbulo superior derecho. }\end{array}$ \\
\hline $\begin{array}{l}\text { Dong et al. }{ }^{13} \\
12 / 5 / 20\end{array}$ & 1 & Posible & Asintomático & $\begin{array}{l}\text { IgM e lgG positivas, a las dos } \\
\text { horas de vida }\end{array}$ & $\begin{array}{l}\text { Rayos X de tórax } \\
\text { Normal. }\end{array}$ \\
\hline $\begin{array}{l}\text { Dumpa et al. }{ }^{20} \\
17 / 5 / 20\end{array}$ & 1 & Posible & $\begin{array}{l}\text { A los } 22 \text { días de edad } \\
\text { historia de } 1 \text { día de fiebre } \\
\text { y falta de apetito. }\end{array}$ & $\begin{array}{l}\text { RT-PCR en hisopado } \\
\text { nasofaríngeo, positiva a los } 22 \\
\text { días de vida. }\end{array}$ & ND. \\
\hline $\begin{array}{l}\text { Abasse et al. }{ }^{19} \\
31 / 5 / 20\end{array}$ & 1 & Posible & $\begin{array}{l}\text { Neumonía a los } 14 \text { días } \\
\text { de vida. }\end{array}$ & $\begin{array}{l}\text { RT-PCR en hisopado } \\
\text { nasofaríngeo, positiva a las } 24 \\
\text { horas y a los } 14 \text { días de vida. }\end{array}$ & $\begin{array}{l}\text { TAC de tórax } \\
\text { Lesiones en vidrio esmerilado } \\
\text { y consolidaciones bilaterales. }\end{array}$ \\
\hline $\begin{array}{l}\text { Demirjian et al. }{ }^{17} \\
10 / 7 / 20\end{array}$ & 1 & Posible & $\begin{array}{l}\text { Fiebre, coriza y taquipnea } \\
\text { leve, al quinto día de vida. }\end{array}$ & $\begin{array}{l}\text { RT-PCR en hisopado } \\
\text { nasofaríngeo, positiva a las } 72 \\
\text { horas de vida. }\end{array}$ & $\begin{array}{l}\text { Rayos X de tórax } \\
\text { Normal. }\end{array}$ \\
\hline $\begin{array}{l}\text { Sisman et al. } \\
10 / 7 / 20\end{array}$ & 1 & Posible & $\begin{array}{l}\text { En el segundo día de } \\
\text { vida presentó fiebre y } \\
\text { dificultad respiratoria con } \\
\text { retracciones subcostales } \\
\text { mínimas, taquipnea e } \\
\text { hipoxia. }\end{array}$ & $\begin{array}{l}\text { RT-PCR en hisopado } \\
\text { nasofaríngeo, positiva a las } 24 \text { y } \\
48 \text { horas de vida. } \\
\text { Inmunohistoquímica de la } \\
\text { placenta, utilizando anticuerpos } \\
\text { monoclonales contra la proteína } \\
\text { N del SARS-CoV-2: tinción } \\
\text { citoplasmática franca en las } \\
\text { células sincitiotrofoblásticas. }\end{array}$ & $\begin{array}{l}\text { Rayos X de tórax } \\
\text { Normal. }\end{array}$ \\
\hline $\begin{array}{l}\text { Vivanti et al. }{ }^{4} \\
14 / 7 / 20\end{array}$ & 1 & Posible & $\begin{array}{l}\text { Al tercer día de vida inició } \\
\text { irritabilidad, succión } \\
\text { débil, hipertonía axial } \\
\text { y opistotonos; líquido } \\
\text { cefalorraquídeo sin } \\
\text { anomalías, todo resolvió } \\
\text { espontáneamente en } 72 \\
\text { horas. }\end{array}$ & $\begin{array}{l}\text { RT-PCR en hisopados } \\
\text { nasofaríngeo y rectal, sangre y } \\
\text { lavado bronco-alveolar, positivas } \\
\text { a las } 1.5 \text { horas de vida. } \\
\text { Inmunohistoquímica de la } \\
\text { placenta utilizando anticuerpos } \\
\text { monoclonales contra la proteína } \\
\text { N del SARS-CoV-2: intensa } \\
\text { positividad citoplasmática en las } \\
\text { células trofoblásticas perivellosas, } \\
\text { denotando una carga viral alta. }\end{array}$ & $\begin{array}{l}\text { Rayos X de tórax } \\
\text { Normal. } \\
\text { Resonancia magnética } \\
\text { cerebral } \\
\text { Gliosis bilateral en la } \\
\text { materia blanca subcortical y } \\
\text { periventricular. }\end{array}$ \\
\hline $\begin{array}{l}\text { Facchetti et al. }{ }^{5} \\
17 / 8 / 20\end{array}$ & 1 & Posible & $\begin{array}{l}\text { Veinticuatro horas } \\
\text { después del parto } \\
\text { desarrolló fiebre, dificultad } \\
\text { para respirar, vómitos, } \\
\text { distensión abdominal, } \\
\text { hipotonía y eritema } \\
\text { cutáneo leve. Fue } \\
\text { trasladado a la unidad } \\
\text { de cuidados intensivos } \\
\text { donde se le inició } \\
\text { ventilación mecánica. }\end{array}$ & $\begin{array}{l}\text { RT-PCR en hisopado } \\
\text { nasofaríngeo no concluyente al } \\
\text { nacer. } \\
\text { Resultó positiva a las } 36 \text { y } 72 \\
\text { horas de vida y a los } 17 \text { días de } \\
\text { edad. }\end{array}$ & $\begin{array}{l}\text { Rayos X de tórax } \\
\text { Neumonía intersticial. }\end{array}$ \\
\hline
\end{tabular}




\begin{tabular}{|c|c|c|c|c|c|}
\hline Publicación & $\begin{array}{l}\text { Número de } \\
\text { neonatos }\end{array}$ & $\begin{array}{l}\text { Transmisión } \\
\text { vertical }\end{array}$ & Hallazgos clínicos & $\begin{array}{l}\text { Pruebas SARS-CoV- } 2 \text { y edad a } \\
\text { las que fueron realizadas }\end{array}$ & Imagenología \\
\hline $\begin{array}{l}\text { Fenizia et al. }{ }^{6} \\
12 / 10 / 20\end{array}$ & 2 & Posible & $\begin{array}{l}\text { Neonato 1: prematurez } \\
\text { de } 33 \text { semanas, fiebre y } \\
\text { disnea. } \\
\text { Neonato 2: asintomático. }\end{array}$ & $\begin{array}{l}\text { RT-PCR en hisopado } \\
\text { nasofaríngeo, positiva a las } \\
0 \text { horas de vida en ambos } \\
\text { neonatos. } \\
\text { RT-PCR en placenta y plasma } \\
\text { de cordón umbilical de ambos } \\
\text { neonatos, positiva a las } 0 \text { horas } \\
\text { de vida. }\end{array}$ & ND \\
\hline $\begin{array}{l}\text { Dumitriu et al. }{ }^{16} \\
12 / 10 / 20\end{array}$ & 2 & Posible & Asintomáticos & $\begin{array}{l}\text { RT-PCR en hisopado } \\
\text { nasofaríngeo, indeterminada } \\
\text { (indicativo de carga viral baja) } \\
\text { entre las } 24-48 \text { horas de vida en } \\
\text { ambos neonatos. }\end{array}$ & $\begin{array}{l}\text { Rayos } X \text { de tórax } \\
\text { Normal }\end{array}$ \\
\hline
\end{tabular}

Abreviaturas: SARS-CoV-2, coronavirus 2 del síndrome respiratorio agudo grave; RT-PCR, reacción en cadena de la polimerasa-transcriptasa reversa; IgM, inmunoglobulina M; IgG, inmunoglobulina G; TAC, tomografía axial computarizada; USG, ultrasonografía; EEG, electroencefalograma; ND, no datos. Adaptada de: Duran P. COVID-19 and newborn health: systematic review. Rev Panam Salud Pública. 2020; 44:e54. DOI: 10.26633/RPSP.2020.54, Shalish W. COVID-19 and Neonatal Respiratory Care: Current Evidence and Practical Approach. Am J Perinatol. 2020. DOl: 10.1055/s-0040-1710522, Muldoon K. SARS-CoV-2: Is it the Newest Spark in the TORCH? Journal of Clinical Virology. 2020. DOl:10.1016/j.jcv.2020.104372.

Los tres neonatos con resultados equívocos presentaron un curso posnatal sin incidentes ${ }^{13,14}$ (Tabla 1). Los tres presentaron RTPCR negativas en hisopados nasofaríngeos y muestras de sangre. Sin embargo, presentaron niveles séricos elevados de anticuerpos lgM e lgG anti SARS-CoV-2, así como de interleucina 6 (IL-6), en muestras tomadas entre las 0-2 horas de vida. Mientras la presencia de anticuerpos lgM en los tres recién nacidos orienta a la posibilidad de transmisión vertical, los resultados negativos de RTPCR no la apoyan. Además, se recomienda precaución cuando se utilizan ensayos de lgM para hacer el diagnóstico de infecciones congénitas, ya que los resultados falsos positivos son frecuentes ${ }^{23}$.

Los 23 bebés diagnosticados por RT-PCR o IgM/lgG (Tabla 1), fueron identificados entre las 0 horas y las 3 semanas de vida $3,6,11,12,16,18-$ 22,24-27 lo que sugiere que estas infecciones se adquirieron en el útero o posnatalmente.

De los 20 neonatos con RT-PCR positivas o débiles, dieciocho necesitaron apoyo respiratorio: cánula nasal (2), CPAP nasal (3), intubación orotraqueal (12) y no especificado $(1)^{3-6,11,12,19,28-32}$, dos de ellos fallecieron, uno por síndrome de distress respiratorio, neumotórax, choque, falla multiorgánica y coagulación intravascular diseminada ${ }^{31}$, y el otro, debido a un aborto atribuible a un síndrome de dificultad respiratoria aguda y choque materno ${ }^{32}$.

La gran mayoría de los bebés con pruebas negativas, o no evaluados con una prueba de laboratorio, fueron asintomáticos después del nacimiento; una pequeña proporción presentó sintomatología leve ${ }^{10}$.
Di Mascio et al.33 publicó en mayo de 2020, una revisión sistemática y metaanálisis de 41 embarazadas con COVID-19, reportaron que puede haber mayor riesgo de aborto espontáneo, parto prematuro, preeclampsia y parto por cesárea, en aquellas embarazadas hospitalizadas con neumonía. Martínez et al. ${ }^{34}$ reportarón en mayo de 2020, una serie de 82 embarazadas RT-PCR positivas. En esta serie, el parto por cesárea se asoció con un mayor riesgo de ingresar al recién nacido a la unidad de cuidados intensivos neonatales (UCIN).

\section{Cuadro clínico}

Los signos reportados en los recién nacidos con infección por SARS-CoV-2 incluyen: fiebre, rinorrea, tos, taquipnea, disnea, letargo, exantema, vómitos, diarrea, intolerancia a la vía oral y disminución de la ingesta. Muchos de estos hallazgos también pueden ser provocados en recién nacidos, de término o prematuros, por otras razones (por ejemplo, sepsis neonatal, taquipnea transitoria del recien nacido o síndrome de dificultad respiratoria neonatal).

La mayoría de los recién nacidos reportados fueron asintomáticos o presentaron sintomatología leve, recuperándose sin complicaciones. Sin embargo, se reportaron algunos casos graves que requirieron ventilación mecánica. Las manifestaciones clínicas más frecuentes fueron la taquipnea y la disnea ${ }^{10}$.

\section{Análisis de laboratorio e imagenología}




\section{Exámenes generales}

En los exámenes de laboratorio, la leucopenia y la linfopenia son típicas, mientras que la proteína $C$ reactiva y la procalcitonina generalmente están dentro de los valores normales (excepto en casos severos, donde sus niveles aumentan). Otros hallazgos pueden incluir trombocitopenia leve $\mathrm{y} / \mathrm{o}$ valores elevador de las siguientes pruebas: creatina-quinasa, fosfatasa alcalina, alanina aminotransferasa, aspartato aminotransferasa y deshidrogenasa láctica ${ }^{8}$.

\section{RT-PCR y serología}

Dependiendo de la prueba RT-PCR utilizada, la sensibilidad varía del 71 al $98 \% \%^{35}$. En cuanto a la serología, la sensibilidad y especificidad de la IgM anti SARS-CoV-2 son $88,2 \%$ y 99 $\%$, respectivamente y para la lgG anti SARSCoV-2 97,8\% y 97,9\%, respectivamente ${ }^{14}$.

\section{Imagenología}

Las lesiones pulmonares se muestran más claramente mediante la tomografía axial computarizada (TAC) de tórax que mediante los rayos $X$. Los hallazgos comunes en ambas pruebas incluyen: opacidades en vidrio esmerilado o múltiples consolidaciones uni o bilaterales, lobulares o segmentarias, sobre todo en la periferia del parénquima pulmonar ${ }^{8}$.

\section{Tratamiento}

No hay tratamiento antiviral y/o inmunomodulador aprobado para COVID-19 en recién nacidos. La orientación específica para el manejo respiratorio de COVID-19 en neonatos aún no está disponible, ya que los bebés positivos que requirieron apoyo fueron prematuros o presentaban comorbilidades. Por lo tanto, el verdadero impacto del SARSCoV-2 en recién nacidos probablemente surgirá de estudios adicionales en los próximos meses. Sin embargo, mientras tanto, las UCIN deben establecer pautas o protocolos para el manejo de los neonatos con COVID-19, así como para prevenir las infecciones asociadas a la atención en salud' ${ }^{1}$. En ausencia de lineamientos uniformes a la fecha, la relación riesgo/beneficio debe sopesarse cuidadosamente de manera individual, considerando la opinión informada de los padres.

Los recién nacidos pueden ser dados de alta después de la resolución de la sintomatología respiratoria, la ausencia de fiebre por al menos tres a cinco días y después de dos hisopados nasofaríngeos negativos para
SARS-CoV-2, tomados con al menos 48 horas de diferencia ${ }^{8}$.

\section{Cuidados en la atención del parto}

\section{Instalaciones, equipo y personal}

Las madres con COVID-19 positivas o sospechosas, que requieren ingreso para la atención del parto, deben ser ingresadas en una habitación con presión negativa, dedicada exclusivamente a la atención de dichos partos.

El personal responsable de la atención debe solicitar de inmediato equipo de protección personal (EPP) de nivel 2 o nivel 336. Los pacientes deben ser manejados por médicos especialistas, con experiencia y con la protección antes descrita, para evitar la infección cruzada. Se recomienda que las madres utilicen mascarillas quirúrgicas en todo momento.

Se deberá intentar siempre el parto por vía vaginal, y que la cesárea se efectúe por indicación obstétrica, según normativa institucional. Se debe tener precaución con la episiotomía y la aplicación de fórceps. No se recomienda el parto en agua.

No hay evidencia que la analgesia epidural o la anestesia espinal estén contraindicadas, por lo tanto, la analgesia epidural debe recomendarse durante el parto temprano, con el fin de minimizar la necesidad de anestesia general en situaciones de emergencia ${ }^{37}$.

El equipo neonatal debe ser informado lo antes posible del ingreso de un caso confirmado o sospechoso de COVID-19. El equipo de reanimación de sala debe revisarse con antelación.

El equipo de uso común para la reanimación y estabilización neonatal debe estar fácilmente disponible. Todo el equipo de reanimación debe ser exclusivo para el área asignada: cuna térmica, bolsa máscara, equipo de succión, tubos endotraqueales y oxímetro de pulso; se debe evitar mover el equipo dentro y fuera de la sala de partos innecesariamente.

Como no es posible predecir cuales recién nacidos requerirán intubación o succión profunda, el equipo neonatal debe utilizar EPP en todos los partos de mujeres positivas o sospechosas de COVID-19. Siempre se deberá considerar a una madre con intubación endotraqueal como un generador significativo de aerosoles. Además, el parto vaginal espontáneo y la cesárea se consideran situaciones de exposición a fluidos corporales, por lo tanto deben tomarse las precauciones correspondientes contra la COVID-1938.

Si existe una necesidad potencial de procedimientos de generación de aeroso- 
les (succión, ventilación con bolsa máscara, presión positiva continua de la vía aérea (CPAP), intubación/extubación, succión profunda, etc.), el EPP debe incluir un respirador eléctrico purificador de aire (PAPR, por sus siglas en inglés), gafas, respirador N95, bata y guantes. Los anteojos graduados no ofrecen la protección ocular adecuada. Con el adecuado EPP, el riesgo absoluto para los que atienden a estos recién nacidos, y realizan estas maniobras, se considera es bajo ${ }^{39}$.

En el caso de un prematuro, se deben tomar las medidas termorreguladoras estándar, incluido el uso de la bolsa de plástico.

Se recomienda tener una guía disponible sobre los traslados seguros entre servicios, los recién nacidos deben ser transportados en una incubadora cerrada de doble pared. Si el neonato está en soporte respiratorio no invasivo, es imperativo colocar la línea espiratoria dentro de la incubadora ${ }^{40}$. El utilizar incubadoras cerradas para el traslado apropiado de estos pacientes, protege al personal de salud de la aerosolización del virus ${ }^{41}$.

\section{Soporte vital básico y avanzado en neonatos con COVID-19 sospechoso o confirmado}

Si el recién nacido requiere asistencia respiratoria, el personal debe estar capacitado en reanimación y estabilización neonatal según los protocolos actuales del programa Neonatal Advance Life Support (NALS, por sus siglas en inglés) o con base a cualquier guía de reanimación neonatal vigente ${ }^{42}$.

Es poco probable que la atención neonatal de rutina y los pasos iniciales de la reanimación neonatal generen aerosoles; estos incluyen: secado, estimulación táctil, colocación en una bolsa de plástico o envoltura (en el caso de un recién nacido prematuro), evaluación de la frecuencia cardíaca y respiratoria, colocación de oximetría de pulso y monitoreo de signos vitales. La succión es un procedimiento generador de aerosoles y no está indicado en recién nacidos sin complicaciones.

Las pautas actuales no recomiendan la intubación de rutina para neonatos vigorosos o no vigorosos con líquido amniótico teñido de meconio. No se han presentado pruebas que sugieran modificar esta directriz en casos de COVID-19.

El uso de medicamentos por vía endotraqueal, como el factor surfactante o la adrenalina, es un procedimiento generador de aerosoles, especialmente a través de un tubo sin manguito. El suministro intravenoso de epinefrina a través de un catéter venoso umbilical bajo, es la vía de administración preferida durante la reanimación neonatal.
Cuidados de recién nacidos de madres COVID-19 en los servicios de neonatología o UCIN, y pautas de contacto madre-recién nacido

Al nacer el recién nacido debe ser rápidamente evaluado y, si respira espontáneamente, se le cumplen los cuidados básicos y se le coloca en una incubadora de transporte. Si se requiere reanimación avanzada, se le proporciona la asistencia respiratoria necesaria y se debe ingresar a una UCIN, en una sala de presión negativa.

La Academia Americana de Pediatría (AAP), el Colegio Americano de Ginecología y Obstetricia (ACOG) y un consenso de expertos chinos, recomiendan separar a los recién nacidos de las madres con confirmación o sospecha de COVID-19. El presunto beneficio de esta separación temporal, es decir, la disminución del riesgo de infección neonatal, debe ser discutido con las familias antes del parto ${ }^{43}$. Los Centros para el Control y Prevención de Enfermedades (CDC, por sus siglas en inglés) recientemente cambiaron su lineamiento sobre la separación de los recién nacidos de madres COVID-19, confirmado o sospechoso. Recomiendan llevar a cabo la separación de las madres y los recién nacidos, evaluando caso por caso, tomando en cuenta las opiniones de la madre, el padre, la familia y el equipo de atención médica, sobre los riesgos y beneficios de la misma ${ }^{44}$.

Lo anterior contrasta con la conclusión de la OMS al respecto: las madres COVID-19 y sus bebés no deben estar separados, el contacto piel a piel y la lactancia deben ser recomendados porque los beneficios superan cualquier riesgo potencial de infección $n^{45}$.

La Sociedad Española de Neonatología recomienda ${ }^{46}$, en los casos de neonatos asintomáticos, hijos de madres asintomáticas con infección confirmada o en investigación, el alojamiento conjunto con régimen de aislamiento de contacto y gotas (higiene de manos, mascarilla facial y la cuna separada a dos metros de la cama de la madre). Con lo anterior, se evita la separación de la madre de su recién nacido.

En neonatos asintomáticos, hijos de madres sintomáticas con infección confirmada o en investigación, el recién nacido deberá ser ingresado y separado de su madre sólo cuando las condiciones clínicas de esta así lo requieran. La duración de las medidas de aislamiento y separación madre-hijo, debe analizarse de forma individual en relación con los resultados virológicos y las condiciones clínicas del binomio, según las recomendaciones del equipo de vigilancia epidemiológica del hospital. 
Los neonatos sintomáticos deben ser ingresados y manejados según lo indiquen los protocolos propios de la patología neonatal subyacente. Se deben monitorizar las constantes vitales (frecuencia cardíaca, frecuencia respiratoria, temperatura, tensión arterial y saturación de oxígeno) y mantener una vigilancia clínica continua. El soporte nutricional con leche materna, bancos de leche o fórmula, es básico. Según lo amerité cada caso, se valorará la realización de estudios de laboratorio y de imagen, especialmente TAC, USG y/o radiografía de tórax.

El manejo clínico no difiere del de cualquier neonato con la misma sintomatología, aplicando las medidas de soporte que precisen. En casos de distress respiratorio agudo grave, se valorará el uso de surfactante a las dosis habituales, ventilación de alta frecuencia y/o óxido nítrico inhalado. Se insiste en que aun no existe tratamiento específico para SARS-CoV-2 en recién nacidos. Se recomienda evitar el uso inapropiado de antibioterapia, limitándola a los casos de sobreinfección bacteriana confirmada ${ }^{46}$.

Se recomienda la intubación de secuencia rápida para aquellos neonatos en insuficiencia respiratoria con COVID-1947. Si se necesita ventilación con bolsa-máscara, los proveedores deberán colocar un filtro HEPA entre la máscara y la fuente de oxígeno, así como utilizar el EPP completo ${ }^{48}$. Se deben utilizar sistemas cerrados para disminuir el riesgo de aerosolización. El ventilador/oscilador de alta frecuencia, sin circuitos experimentales especializados, no puede filtrar el aire exhalado, haciendo que su uso sea de riesgo para los proveedores de salud durante una epidemia viral ${ }^{48}$. Todo lo anterior se presenta en la Tabla 2.

Tabla 2. Opciones basadas en la toma de decisiones compartidas con los padres, para manejar a un recién nacido de una madre con COVID-19 sospechoso o confirmado

\begin{tabular}{|c|c|c|c|}
\hline Escenario & Opción A & Opción B & Opción C \\
\hline Parto & $\begin{array}{l}\text { Precauciones necesarias según } \\
\text { lo recomendado por los CDC, } \\
\text { para el parto y la reanimación, } \\
\text { en una habitación con presión } \\
\text { negativa. }\end{array}$ & $\begin{array}{l}\text { Precauciones necesarias según lo } \\
\text { recomendado por los CDC, en una } \\
\text { habitación con presión negativa o una } \\
\text { habitación aislada. }\end{array}$ & $\begin{array}{l}\text { Precauciones necesarias según lo } \\
\text { recomendado por los CDC, en una } \\
\text { habitación aislada. }\end{array}$ \\
\hline $\begin{array}{l}\text { Reanimación } \\
\text { neonatal }\end{array}$ & $\begin{array}{l}\text { La reanimación se realiza en } \\
\text { una habitación separada, con } \\
\text { presión negativa. }\end{array}$ & $\begin{array}{l}\text { La reanimación se realiza a seis pies o } \\
\text { a dos metros de distancia de la madre, } \\
\text { utilizando una cortina o barrera física, } \\
\text { con mínimo personal, en una habitación } \\
\text { con presión negativa. }\end{array}$ & $\begin{array}{l}\text { La reanimación se realiza a seis pies o } \\
\text { a dos metros de distancia de la madre, } \\
\text { con mínimo personal, en una habitación } \\
\text { aislada. }\end{array}$ \\
\hline $\begin{array}{l}\text { Pinzamiento tardío } \\
\text { del cordón umbilical }\end{array}$ & $\begin{array}{l}\text { No pinzamiento tardío } \\
\text { del cordón bajo ninguna } \\
\text { circunstancia. }\end{array}$ & $\begin{array}{l}\text { Pinzamiento tardío del cordón en } \\
\text { madres asintomáticas o levemente } \\
\text { sintomáticas. }\end{array}$ & $\begin{array}{l}\text { Pinzamiento tardío del cordón en todas } \\
\text { las madres. }\end{array}$ \\
\hline $\begin{array}{l}\text { Contacto piel con } \\
\text { piel }\end{array}$ & No contacto piel con piel. & $\begin{array}{l}\text { Contacto piel con piel solo con madres } \\
\text { asintomáticas (previo lavado de manos y } \\
\text { uso de mascarilla de parte de la madre). }\end{array}$ & $\begin{array}{l}\text { Contacto piel con piel solo con madres } \\
\text { asintomáticas o levemente sintomáticas } \\
\text { (previo lavado de manos y uso de } \\
\text { mascarilla de parte de la madre). }\end{array}$ \\
\hline $\begin{array}{l}\text { Ubicación del recién } \\
\text { nacido }\end{array}$ & $\begin{array}{l}\text { En habitación aislada, con } \\
\text { presión negativa, en cuidados } \\
\text { mínimos, intermedios o } \\
\text { intensivos, dependiendo de } \\
\text { la condición clínica, la edad } \\
\text { gestacional y el peso al nacer. }\end{array}$ & $\begin{array}{l}\text { Neonato en aislamiento en habitación } \\
\text { con presión negativa, visitas de la madre } \\
\text { con mascarilla y realizando, cuidadosa y } \\
\text { frecuentemente, higiene de manos. }\end{array}$ & $\begin{array}{l}\text { En la misma habitación con la madre, } \\
\text { colocado a una distancia de } 6 \text { pies } \\
\text { o } 2 \text { metros de ella, excepto durante } \\
\text { la alimentación. Durante la lactancia } \\
\text { materna la madre debe utilizar } \\
\text { siempre mascarilla y lavarse las manos } \\
\text { frecuentemente. }\end{array}$ \\
\hline $\begin{array}{l}\text { Exámenes al recién } \\
\text { nacido }\end{array}$ & $\begin{array}{l}\text { Hisopados nasofaríngeo, } \\
\text { orofaríngeo y rectal, a las } 24 \text { y } \\
48 \text { horas de vida (dos por cada } \\
\text { sitio corporal). }\end{array}$ & $\begin{array}{l}\text { Hisopado nasofaríngeo/orofaríngeo a } \\
\text { las } 24 \text { horas de vida (2-3 hisopados). }\end{array}$ & $\begin{array}{l}\text { No toma de exámenes en neonatos } \\
\text { asintomáticos. }\end{array}$ \\
\hline $\begin{array}{l}\text { Exámenes maternos } \\
\text { para finalizar las } \\
\text { medidas preventivas } \\
\text { de transmisión }\end{array}$ & $\begin{array}{l}\text { Madre afebril (sin } \\
\text { antipiréticos), con mejoría de } \\
\text { los síntomas y } 2 \text { hisopados } \\
\text { nasofaríngeos y orofaríngeos } \\
\text { SARS-CoV-2 negativos, con al } \\
\text { menos } 24 \text { horas de diferencia. }\end{array}$ & $\begin{array}{l}\text { Madre afebril (sin antipiréticos), con } \\
\text { mejoría de los síntomas y además, un } \\
\text { hisopado nasofaríngeo y un hisopado } \\
\text { orofaríngeo SARS-CoV-2 negativos. }\end{array}$ & $\begin{array}{l}\text { Afebril (sin antipiréticos) y } \\
\text { mejoría de los síntomas. }\end{array}$ \\
\hline
\end{tabular}




\begin{tabular}{|c|c|c|c|}
\hline Soporte nutricional & $\begin{array}{l}\text { Fórmula, o leche de donante } \\
\text { si está disponible; si la } \\
\text { madre eventualmente desea } \\
\text { brindar seno materno, debe } \\
\text { extraer su leche por bomba } \\
\text { y descartarla, hasta que se } \\
\text { encuentre asintomática, con } \\
\text { dos pruebas SARS-CoV-2 } \\
\text { negativas, con al menos } 24 \\
\text { horas de diferencia. }\end{array}$ & $\begin{array}{l}\text { Senos limpios; leche materna extraída } \\
\text { por bomba y administrada por un } \\
\text { recurso de salud sano. }\end{array}$ & $\begin{array}{l}\text { Lactancia materna: la madre usa EPP, } \\
\text { y con sus senos limpios, amamanta al } \\
\text { recien nacido. }\end{array}$ \\
\hline Visitas al neonato & $\begin{array}{l}\text { Restringir las visitas de } \\
\text { la madre hasta que esté } \\
\text { asintomática y presente } \\
\text { dos pruebas SARS-CoV-2 } \\
\text { negativas. Restringir visitas de } \\
\text { otros familiares. } \\
\text { De contar con las condiciones, } \\
\text { se preferirá la video llamada. }\end{array}$ & $\begin{array}{l}\text { La madre puede visitar. } \\
\text { Restringir a otros visitantes. } \\
\text { Se permite la video llamada }\end{array}$ & $\begin{array}{l}\text { Un visitante (padre o abuelos) con RT-PCR } \\
\text { negativa podría visitar a la madre y al } \\
\text { recién nacido. }\end{array}$ \\
\hline $\begin{array}{l}\text { Neonato expuesto a } \\
\text { un recurso de salud } \\
\text { COVID-19 positivo }\end{array}$ & $\begin{array}{l}\text { Se aisla al bebé en una } \\
\text { habitación con presión } \\
\text { negativa. Se reanuda el } \\
\text { cuidado regular solo después } \\
\text { de obtener dos muestras } \\
\text { del recién nacido negativas, } \\
\text { con al menos } 24 \text { horas de } \\
\text { diferencia. El neonato debe } \\
\text { estar asintomático. }\end{array}$ & $\begin{array}{l}\text { Mantener al bebé en aislamiento hasta } \\
\text { obtener dos muestras negativas, con } \\
\text { al menos } 24 \text { horas de diferencia. El } \\
\text { neonato debe estar asintomático. }\end{array}$ & $\begin{array}{l}\text { Se debe efectuar la prueba al neonato } \\
\text { solo si es sintomático. }\end{array}$ \\
\hline $\begin{array}{l}\text { Plan de alta y } \\
\text { atención posterior } \\
\text { al alta }\end{array}$ & $\begin{array}{l}\text { El recién nacido podría estar } \\
\text { al cuidado de un recurso de } \\
\text { salud sano, hasta que la madre } \\
\text { este afebril (sin antipiréticos), } \\
\text { con mejoría de los } \\
\text { síntomas y con } 2 \text { hisopados } \\
\text { nasofaríngeos y orofaríngeos } \\
\text { SARS-CoV-2 negativos, con al } \\
\text { menos } 24 \text { horas de diferencia. }\end{array}$ & $\begin{array}{l}\text { Alta con la madre con precauciones de } \\
\text { contacto y gota, hasta que la madre esté } \\
\text { afebril (sin antipiréticos), con mejoría } \\
\text { de los síntomas y con } 2 \text { hisopados } \\
\text { nasofaríngeos y orofaríngeos SARS- } \\
\text { CoV-2 negativos, con al menos } 24 \text { horas } \\
\text { de diferencia. }\end{array}$ & $\begin{array}{l}\text { Dar de alta al bebé junto con la madre, } \\
\text { con medidas de precaución de contacto } \\
\text { y gota; no más pruebas maternas a } \\
\text { menos que los signos/síntomas no se } \\
\text { resuelvan en } 14 \text { días, o su condición se } \\
\text { deteriore. }\end{array}$ \\
\hline $\begin{array}{l}\text { Pruebas y } \\
\text { seguimiento al } \\
\text { neonato después } \\
\text { del alta }\end{array}$ & $\begin{array}{l}\text { Hisopados nasofaríngeo y } \\
\text { orofaríngeo a las 2-3 semanas } \\
\text { después del alta. } \\
\text { De contar con las condiciones, } \\
\text { se preferirá la video llamada. }\end{array}$ & $\begin{array}{l}\text { Si previamente fueron negativos, se } \\
\text { tomarán hisopados nasofaríngeo y } \\
\text { orofaríngeo a las 2-3 semanas después } \\
\text { del alta. } \\
\text { De contar con las condiciones, se } \\
\text { preferirá la video llamada. }\end{array}$ & $\begin{array}{l}\text { No se deben realizar más pruebas a } \\
\text { menos que el bebé esté sintomático. } \\
\text { De contar con las condiciones, se } \\
\text { preferirá la video llamada. }\end{array}$ \\
\hline $\begin{array}{l}\text { Riesgo potencial } \\
\text { de transmisión al } \\
\text { neonato }\end{array}$ & Bajo & Desconocido pero posible & Desconocido pero podría ser moderado. \\
\hline
\end{tabular}

Abreviaturas: CDC, Centros para el Control y Prevención de Enfermedades; COVID-19, enfermedad por coronavirus-19; EPP, equipo de protección personal, SAR-CoV-2, coronavirus 2 del síndrome respiratorio agudo grave.

Nota: cada opción detallada en esta tabla puede modificarse según la preferencia institucional para desarrollar una política individual basada en los recursos disponibles, las instalaciones y el volumen de pacientes. El factor predominante que impulsa estas elecciones es la aceptación materna del riesgo de transmisión. Cada centro puede adoptar diferentes opciones para cada fila y desarrollar su propio algoritmo.

Adaptada de: Chandrasekharan P, Vento M, Trevisanuto D, Partridge E, Underwood M, Wiedeman J, et al. Neonatal resuscitation and post resuscitation care of infants born to mothers with suspected or confirmed SARS-CoV-2 infection. Am J Perinatol. 2020;37:813-824.DOI: 10.1055/s0040-1709688 


\section{Lineamientos sobre la alimentación con seno materno durante a la pandemia de COVID-19}

Se ha demostrado que el inicio temprano de la lactancia materna tiene efectos positivos en el recién nacido, especialmente cuando se realiza dentro de la primera hora después del nacimiento. La leche materna es el mejor nutriente para los recién nacidos, ya que contiene anticuerpos que mejoran su sistema inmunológico ${ }^{49}$.

Una revisión sistemática, que siguió los procedimientos del manual Cochrane, identificó estudios que incluyeron a madres con sospecha o confirmación de COVID-19 y a sus bebés. La búsqueda se realizó en MEDLINE (PubMed), la literatura mundial de la OMS sobre COVID-19 (https://search.bvsalud.org/global-literature-on-novel-coronavirus-2019-ncov/), la librería Cochrane, la Web of Science Core Collection y Embase. También realizaron búsquedas en la Plataforma de registros de ensayos clínicos internacionales sobre COVID-19 de la OMS, con el fin de identificar estudios en curso o no publicados. La búsqueda identificó inicialmente 19414 registros, de los cuales, 7926 títulos y resúmenes se analizaron después de eliminar los duplicados. Se evaluó la elegibilidad de 605 artículos de texto completo, excluyendo 265. De los 340 restantes, solo 37 investigaron la presencia del SARS-CoV-2 en las muestras de leche materna. La revisión mostró que la evidencia no es suficiente al momento para concluir que existe transmisión vertical del SARS-CoV-2 a través de la lactancia materna ${ }^{50}$.

\section{Conclusiones}

Los estudios realizados orientan a que la transmisión vertical de SARS-CoV-2 por vía transplacentaria, aunque rara, es posible, y a la vez, confirman dicha transmisión en el ámbito posnatal. Su transmisión durante el parto aún no ha sido documentada. La lactancia materna debe tenerse en mente como posible mecanismo de transmisión, a menos que se demuestre lo contrario en futuros estudios.

La mayoría de neonatos infectados por SARS-CoV-2 son asintomáticos o muestran sintomatología leve, aunque han sido reportados casos graves, con necesidad de apoyo ventilatorio. No hay tratamiento antiviral y/o inmunomodulador aprobado para COVID-19 en recién nacidos. Las unidades de cuidados intensivos neonatales deben establecer pautas o protocolos de manejo de soporte (sobre todo apoyo respiratorio) para estos pacientes, según lo ameriten.

La decisión de mantener separado al binomio debe ser individualizada, teniendo en cuenta la situación clínica y de laboratorio de la madre y el neonato, así como los lineamientos hospitalarios locales. En general, se debe permitir que los recién nacidos compartan la habitación con sus madres, estimulando a la vez, la lactancia materna desde el nacimiento, siempre y cuando las condiciones clínicas del neonato y la madre, lo permitan.

\section{Financiamiento}

La revisión fue financiada por los investigadores.

\section{Referencias bibliográficas}

1. Muldoon KM, Fowler KB, Pesch MH, Schleiss MR. SARS-CoV-2: is it the newest spark in the TORCH? J Clin Virol. 2020;127:104372. DOI: 10.1016/j.jcv.2020.104372

2. Penfield CA, Brubaker SG, Limaye MA, Lighter J, Ratner AJ, Thomas KM, et al. Detection of severe acute respiratory syndrome coronavirus 2 in placental and fetal membrane samples. Am J Obstet Gynecol MFM. 2020;2(3):100133. DOI: 10.1016/j.ajogmf.2020.100133

3. Sisman J. Intrauterine Transmission of SARS-COV-2 Infection in a Preterm Infant. The Pediatric Infectious Disease Journal. 2020; 39 (9):e265-e267. DOI: 10.1097/ INF.00000000000002815

4. Vivanti AJ, Vauloup-Fellous C, Prevot S, Zupan V, Suffee C, Do Cao J, et al. Transplacental transmission of SARS-CoV-2 infection. Nat Commun. diciembre de 2020;11(1):3572. DOI: 10.1038/s41467-020-17436-6

5. Facchetti F, Bugatti M, Drera E, Tripodo C, Sartori E, Cancila V, et al. SARS-CoV2 vertical transmission with adverse effects on the newborn revealed through integrated immunohistochemical, electron microscopy and molecular analyses of Placenta. EBioMedicine. 2020;59:102951. DOI: 10.1016/j.ebiom.2020.102951

6. Fenizia C. Analysis of SARS-CoV-2 vertical transmission during pregnancy. Nature Communications. 2020;11:5128. DOI: 10.1038/s41467-020-18933-4

7. Green J, Petty J, Bromley P, Walker K, Jones L. COVID-19 in babies: Knowledge for neonatal care. J Neonatal Nurs. 2020;26(5):239-46. DOI: $10.1016 /$ j.jnn.2020.06.005

8. De Rose DU, Piersigilli F, Ronchetti MP, Santisi A, Bersani l, et al. Novel Coronavirus disease (COVID-19) in newborns and infants: what 
we know so far. Ital J Pediatr. 2020;46(1):56. DOI: 10.1186/s13052-020-0820-x

9. Groß R, Conzelmann C, Müller JA, Stenger S, Steinhart K, Kirchhoff F, et al. Detection of SARS-CoV-2 in human breastmilk. The Lancet. 2020; 395(10239):1757-8. DOl: 10.1016/S0140-6736(20)31181-8

10. Shalish W, Lakshminrusimha S, Manzoni P, Keszler M, Sant'Anna GM. COVID-19 and neonatal respiratory care: current evidence and practical approach. Am J Perinatol. 2020. DOI: 10.1055/s-0040-1710522

11. Ng KF, Bandi S, Bird PW, Wei-Tze Tang J. COVID-19 in neonates and infants: progression and recovery. Pediatr Infect Dis J. 2020. DOI: 10.1097/INF.0000000000002738

12. Coronado Munoz A, Nawaratne U, McMann D, Ellsworth M, Meliones J, Boukas K. Lateonset neonatal sepsis in a patient with Covid-19. N Engl J Med. 2020;382(19):e49. DOI: 10.1056/NEJMc2010614

13. Dong L, Tian J, He S, Zhu C, Wang J, Liu C, et al. Possible vertical transmission of SARS-CoV-2 from an infected mother to her newborn. JAMA. 2020. DOI: 10.1001/jama.2020.4621

14. Zeng H, Xu C, Fan J, Tang Y, Deng Q, Zhang $W$, et al. Antibodies in infants born to mothers with COVID-19 pneumonia. JAMA. 2020. DOI: 10.1001/jama.2020.4861

15. Salvatore CM, Han J-Y, Acker KP, Tiwari P, Jin J, Brandler $\mathrm{M}$, et al. Neonatal management and outcomes during the COVID-19 pandemic: an observation cohort study. Lancet Child Adolesc Health. 2020;4(10):721-7. DOl: 10.1016/S2352-4642(20)30235-2

16. Dumitriu D, Emeruwa UN, Hanft E, Liao GV, Ludwig E, Walzer L, et al. Outcomes of Neonates Born to Mothers With Severe Acute Respiratory Syndrome Coronavirus 2 Infection at a Large Medical Center in New York City. JAMA Pediatr. 2020. DOI:10.1001/ jamapediatrics.2020.4298

17. Demirjian A, Singh C, Tebruegge M, Herbert R, Draz N, Mirfenderesky M, et al. Probable Vertical Transmission of SARS-CoV-2 Infection. Pediatr Infect Dis J. 2020. DOI: 10.1097/INF.0000000000002821

18. Zamaniyan M, Ebadi A, Aghajanpoor S, Rahmani Z, Haghshenas M, Azizi S. Preterm delivery, maternal death, and vertical transmission in a pregnant woman with COVID-19 infection. Prenat Diagn. 2020; pd.5713. DOI: 10.1002/pd.5713

19. Abasse $S$, Essabar L, Costin T, Mahistra V, Kaci M, Braconnier A, et al. Neonatal COVID-19 Pneumonia: Report of the First Case in a Preterm Neonate in Mayotte, an Overseas Department of France. MEDICINE \& PHARMACOLOGY; 2020. DOI: 10.20944/ preprints202005.0482.v1

20. Dumpa V, Kamity R, Vinci AN, Noyola E, Noor A. Neonatal Coronavirus 2019 (COVID-19) Infection: A Case Report and Review of
Literature. Cureus. 2020. DOI: 10.7759/ cureus. 8165

21. Chacón-Aguilar R, Osorio-Cámara JM, Sanjurjo-Jimenez I, González-González C, López-Carnero J, Pérez-Moneo B. COVID-19: síndrome febril y clínica neurológica en neonato. An Pediatría. 2020;92(6):373-4. DOI: 10.1016/j.anpedi.2020.04.012

22. Zimmermann P, Curtis N. COVID-19 in Children, Pregnancy and Neonates: A Review of Epidemiologic and Clinical Features. Pediatr Infect Dis J. 2020;39(6):469_ 77. DOI: 10.1097/INF.0000000000002700

23. Kimberlin DW, Stagno S. Can SARS-CoV-2 infection be acquired in utero? More Definitive Evidence Is Needed. JAMA. 2020. DOI: 10.1001/jama.2020.4868

24. Wang $X$, Zhou Z, Zhang J, Zhu F, Tang Y, Shen X. A case of 2019 Novel coronavirus in a pregnant woman with preterm delivery. Clin Infect Dis. 2020:ciaa200. DOI: 10.1093/ $\mathrm{cid} / \mathrm{ciaa200}$

25. Yu N, Li W, Kang Q, Xiong Z, Wang S, Lin $X$, et al. Clinical features and obstetric and neonatal outcomes of pregnant patients with COVID-19 in Wuhan, China: a retrospective, single-centre, descriptive study. Lancet Infect Dis. 2020;20(5):559-64. DOI: 10.1016/S1473-3099(20)30176-6

26. Zeng L, Xia S, Yuan W, Yan K, Xiao F, Shao $J$, et al. Neonatal early-onset infection with SARS-CoV-2 in 33 neonates born to mothers with COVID-19 in Wuhan, China. JAMA Pediatr. 2020. DOI: 10.1001/ jamapediatrics.2020.0878

27. Alonso Díaz C, López Maestro M, Moral Pumarega MT, Flores Antón B, Pallás Alonso C. First case of neonatal infection due to COVID-19 in Spain. An Pediatría Engl Ed. 2020;92(4):237-8. DOI: 10.1016/j. anpede.2020.03.002

28. Chen $Y$, Peng $H$, Wang $L$, Zhao $Y$, Zeng $L$, Gao H, et al. Infants Born to Mothers With a New Coronavirus (COVID-19). Front Pediatr. 2020;8:104. DOI: 10.3389/fped.2020.00104

29. Gidlöf S, Savchenko J, Brune T, Josefsson H. COVID-19 in pregnancy with comorbidities: More liberal testing strategy is needed. Acta Obstet Gynecol Scand. 2020:aogs.13862. DOI: 10.1111 /aogs.13862

30. Ancora G. La gestione del neonato con infezione SARS-COV-2 Non è stata documentata per questo virus una trasmissione verticale: nessun neonato da mamma positiva è risultato positivo al virus. SININFORMA. 2020;(78):1-5. Fecha de consulta: 12 de septiembre de 2020. Disponible en: https://www.sicp.it/ wp-content/uploads/2020/03/Gestioneneonato-infezione-covid Sin-magazinemarzo cprd.pdf

31. Zhu H, Wang L, Fang C, Peng S, Zhang $L$, Chang $G$, et al. Clinical analysis of 10 
neonates born to mothers with 2019-nCoV pneumonia. Transl Pediatr. 2020;9(1):51-60. DOI: $10.21037 /$ tp.2020.02.06

32. Liu Y, Chen H, Tang K, Guo Y. Clinical manifestations and outcome of SARSCoV-2 infection during pregnancy. J Infect. 2020:S0163445320301092. DOI: 10.1016/j. jinf.2020.02.028

33. Di Mascio D. Outcome of coronavirus spectrum infections (SARS, MERS, COVID-19) during pregnancy: a systematic review and meta-analysis. Am J Obstet Gynecol MFM. 2020;2(2):100107. DOI: 10.1016/j. ajogmf.2020.100107

34. Martínez-Perez O, Vouga M, Cruz Melguizo S, Forcen Acebal L, Panchaud A, MuñozChápuli M, et al. Association between mode of delivery among pregnant women with COVID-19 and maternal and neonatal outcomes in Spain. JAMA. 2020 DOI: 10.1001/jama.2020.10125

35. Watson J, Whiting PF, Brush JE. Interpreting a COVID-19 test result. BMJ. 2020;369:m1808 DOl: 10.1136/bmj.m1808

36. Law BHY, Cheung P-Y, Aziz K, Schmölzer GM. Effect of COVID-19 Precautions on Neonatal Resuscitation Practice: A Balance Between Healthcare Provider Safety, Infection Control, and Effective Neonatal Care. Front Pediatr. 2020;8:478. DOI: 10.3389/fped.2020.00478

37. Coronavirus (COVID-19) Infection in Pregnancy. Royal College of Obstetricians and Gynaecologists. 2020. Fecha de consulta: 12 de septiembre de 2020. Disponible en: https://www.rcog.org.uk/ coronavirus-pregnancy

38. Chandrasekharan $P$, Vento $M$, Trevisanuto $D$ Partridge $\mathrm{E}$, Underwood $\mathrm{M}$, et al. Neonatal resuscitation and post resuscitation care of infants born to mothers with suspected or confirmed SARS-CoV-2 infection. Am J Perinatol. 2020. DOI: 10.1055/s-00401709688

39. British Association of Perinatal Medicine. COVID-19 - guidance for neonatal settings. Royal College of Paediatrics and Child Health. 2020. Fecha de consulta: 12 de septiembre de 2020. Disponible en: https:// www.rcpch.ac.uk/resources/covid-19guidance-neonatal-settings

40. Chen D, Yang H, Cao Y, et al. Expert consensus for managing pregnant women and neonates born to mothers with suspected or confirmed novel coronavirus (COVID-19) infection. Int J Gynaecol Obstet. 2020;149(2):130-136. DOl: 10.1002/ ijgo.13146

41. Edelson DP, Sasson C. AHA Interim guidance for basic and advanced life support in adults, children, and neonates with suspected or confirmed COVID-19. Circulation. 2020;141(25):e933-e943. DOl: 10.1161/ CIRCULATIONAHA.120.047463

42. American Academy of Pediatrics and American Heart Association; Weiner GM, Zaichkin J, eds. Textbook of Neonatal Resuscitation (NRP). 7th ed. Grove Village, IL: American Academy of Pediatrics; 2016:326

43. Puopolo KM, Hudak ML, Kimberlin DW, Cummings J. Initial guidance: management of infants born to mothers with COVID-19. American Academy of Pediatrics. 2020. Fecha de consulta: 12 de septiembre de 2020. Disponible en: https://downloads.aap. org/AAP/PDF/COVID\%2019\%20Initial\%20 Newborn\%20Guidance.pdf

44. Interim considerations for infection prevention and control of coronavirus disease 2019 (COVID-19) in inpatient obstetric healthcare settings. Centers for Disease Control and Prevention. 2020. Fecha de consulta: 14 de septiembre de 2020.Disponible en: https://snlg.iss.it/ wp-content/uploads/2020/03/05 CDC Interim-Considerations-for-InfectionPrevention-and-Control-COVID19.pdf

45. Scientific brief. Breastfeeding and COVID-19. World Health Organization. 2020. Fecha de consulta: 14 de septiembre de 2020. Disponible en: https://www.who.int/ publications/i/item/10665332639

46. Recomendaciones para el manejo del recién nacido en relación con la infección por SARS-CoV-2. Sociedad Española de Neonatología. 2020. Fecha de consulta: 14 de septiembre de 2020. Disponible en: https://www.seneo.es/images/site/COVID/ Recomendaciones SENeo SARS-CoV-2 Version 6.2 27052020.pdf

47. Chavez S, Long B, Koyfman A, Liang SY. Coronavirus disease (COVID-19): a primer for emergency physicians. Am J Emerg Med. 2020. DOI: 10.1016/j.ajem.2020.03.036

48. Donic V, Torok P, Tomori Z. Noninvasive ventilation in high-risk infections and mass casualty events. New York: Springer; 2014. 45-47 p.

49. Position Paper. COVID-19 and breastfeeding. World Health Organization. 2020. Fecha de consulta: 3 de septiembre de 2020. Disponible en: https://www.euro.who. int/data/assets/pdf file/0010/437788/ breastfeeding-COVID19.pdf

50. Centeno-Tablante E, Medina-Rivera M, Finkelstein $\mathrm{J}$, et al. Transmission of SARS-CoV-2 through breast milk and breastfeeding: a living systematic review. Ann N Y Acad Sci. 2020. DOI: 10.1111/ nyas. 14477 